\title{
Effects of preservatives used in ocular medications on the eye: a comparative review
}

\author{
Rupankar Sarkar \\ NIMS Medical College and Hospital, NIMS University, Jaipur, India
}

\begin{abstract}
Preservatives are added to eye drops in order to increase the shelf life of these medications. However, these preservatives may have some adverse effects on the eye. Various adverse effects of preserved ocular medications have been pointed out by multiple investigators time and again. These preservatives are added to most ocular medicines in today's practice. Given the fact that many patients need to instill these medications for long periods, such as anti-glaucoma medications, the adverse effects of these preservatives need to be taken into account. Benzalkonium chloride is the most widely used preservative in ocular medications and has a lot of adverse effects. Various other alternative preservatives have been developed in more recent times. In this article, a broad overview regarding various researches exploring the different adverse effects of these preservatives has been compiled and presented comparatively.
\end{abstract}

KEY WORDS: preservatives; ocular preservatives; benzalkonium chloride; ocular surface tolerance; ocular tolerance; adverse effects; ocular preservative toxicity

Ophthalmol J 2021; Vol. 6, 44-52

\section{INTRODUCTION}

Preservatives are added to topical ophthalmic drug solutions in order to prevent contamination with pathogenic organisms. In other words, preservatives increase the shelf life of ocular medications.

Preservatives used in ocular medications are categorized into two broad categories: detergents and oxidizing agents. More recently, ionic-buffer system preservatives have been introduced.

Detergents exert their effect by disrupting the cell membrane's lipid layer leading to cell membrane instability and extrusion of bacterial cell contents. Benzalkonium chloride (BAK), polyquaternium-1 (Polyquad), and cetrimonium are examples of detergent preservatives [1].

Oxidizing preservatives are considered second-generation ocular preservatives that exert their effect by penetrating the cell and altering the DNA, protein, and lipid component of the bacterial cell [2]. Oxidizing preservatives are considered to be less harmful to the ocular surface cells. Noecker et al. has reported the preservative stabilized oxychloro complex (SOC) (Purite) to be less toxic to the cornea than BAK [3]. Sodium perborate and SOC are examples of oxidizing preservatives.

Ionic-buffer systems are the latest addition in the classification of preservatives. This class of preservatives acts similarly to the oxidizing preservatives. SofZia (Alcon, TX, USA) is an example of this class and is constituted by zinc, sorbitol, boric acid, and propylene glycol. This has both antibacterial and antifungal qualities. Moreover, on being exposed to cations, such as those in the tear film, the 
substance becomes inactive and thus is less cytotoxic to the ocular surface [4].

Of the many preservatives, BAK is the most commonly used preservative [2]. BAK is a quaternary ammonium compound that exerts its microbicidal action by disrupting the microorganisms' cell membranes. First introduced way back in 1910 as a germicide, it soon found a wide array of uses. By 1940 it was being used in toilet products such as: aftershave, mouthwash, handwashes, laundry detergents, softeners for textiles, deodorants, hair products, sanitizers, in medical products like nasal sprays, spermicides, disinfectants for surgical instruments, burn and ulcer treatment, preoperative skin disinfectants and so on. BAK was initially used in solutions for preserving hard contact lenses, which was perhaps the first use of BAK in ophthalmology. BAK is undoubtedly the most frequently used preservative in topical eye drops today, used in concentration ranges from $0.004 \%$ to $0.02 \%$. BAK is used so frequently as a preservative because of its extreme efficacy in tackling microbial contamination of eye drops and its capability to disrupt cell-cell junctions in the corneal epithelium, thus allowing drug particles of topical eye drops to enter the anterior chamber. Besides, on account of being out there for such a long time, BAK is very familiar to those who are formulating topical ophthalmic drug solutions. Hence is the most commonly used preservative in eye drop formulations [2].

However, there have been concerns regarding the safety profile of BAK, especially considering its adverse effects on the ocular surface.

\section{LITERATURE REVIEW METHOD}

A thorough literature search was made using keywords "ocular preservatives", "benzalkonium chloride", "adverse effects", "ocular surface tolerance", "adverse effects", "ocular adverse effects", "ocular surface health", in PubMed, Google Scholar and Directory of Open Access Journals. All the relevant articles discussing adverse effects of preservatives in eye drops, comparing two or more preservatives in terms of adverse effects or ocular tolerance, were shortlisted. The references from these articles were also looked into, and the relevant ones were added to the list. The summaries of these articles were noted down and later categorized. Some repetitive articles were discarded.

\section{BAK AND OCULAR SURFACE}

Most of the literature and peer-reviewed articles on preservative toxicity focuses on BAK as it is the most commonly used preservative and perhaps is the most toxic of all. BAK can accumulate in ocular tissues and induce changes in the conjunctiva and cornea which may manifest as an ocular surface disease (OSD). OSD occurrence is reportedly as high as thrice that of the general population in patients on chronic anti-glaucoma medications [5].

Following are the reported adverse effects of BAK on different ocular structures.

\section{Tear film}

The detergent action of BAK affects the lipid layer and affects tear film stability decreasing the tear break up time (BUT). One randomized crossover study compared topical carteolol with and without BAK. It was evident that the BAK-containing solution significantly decreased the tear break-up time compared to baseline values in healthy volunteers [6]. In another randomized prospective trial by Aihara et al., switching from BAK preserved latanoprost to SofZia preserved travoprost significantly improved the tear break-up time when the switching was done after three months of therapy with the former, while there was no significant change in tear break-up time in those who had continued therapy with BAK preserved latanoprost [7]. In another study, tear break-up time was reported to be significantly lower from baseline following three months of treatment with BAK preserved travoprost [5]. Crichton et al. have reported tear film instability after treatment for 12 weeks with different preserved prostaglandin analogues; no difference in BUT was reported across the various drug groups though [8]. Rossi et al. have reported that dry eye disease occurs significantly more frequently in glaucoma patients on topical medications [9]. Uusitalo et al. conducted a study in which patients with ocular signs and symptoms of OSD were treated with BAK-preserved latanoprost eye drops (containing 0.02\% benzalkonium chloride). They then were switched to receive preservative-free tafluprost and followed up for 12 weeks. The tear break-up time reportedly improved significantly from $4.5 \pm 2.5$ seconds at baseline to $7.8 \pm 4.9$ seconds at 12 weeks, which was statistically significant. Schirmer test scores improved too, and the results were statistically significant at six weeks. The percentage of patients who had abnormal Schirmer test result at baseline had 
decreased from $71.5 \%$ to $61.5 \%$ at six weeks and to $59.4 \%$ at 12 weeks [10].

The author of the present article had evaluated the long-term effects of anti-glaucoma medications with and without BAK on tear film stability. In this study, newly diagnosed glaucoma patients were started on either preservative-free travoprost $0.004 \%$ or Latanoprost $0.005 \%$ preserved with $0.02 \%$ BAK. After one year of follow-up, a more significant number of patients instilling BAK-preserved drops had tear film instability compared to those instilling preservative-free drops and controls [11].

\section{Conjunctiva}

In an in vitro study demonstrating the effects of preservative-free and preserved prostaglandin analogues on cultured human conjunctival fibroblasts, it was seen that BAK induced apoptosis caused cell shrinkage and reduced cell viability in a dose-dependent fashion [12]. In another in vitro study, latanoprost with BAK, travoprost with BAK, and BAK alone had significant cytotoxic effects on human conjunctiva-derived cells and were associated with apoptosis [13]. In another study, the toxicity on cultured human corneal and conjunctival cells related to the prostaglandin analogs latanoprost, tafluprost, and travoprost preserved with BAK was similar to the toxicity observed in their respective BAK concentrations. It proved the fact that the drugs themselves are not toxic to the conjunctival cells. In that same study, it SofZia preserved travoprost, and polyquad containing travoprost had significantly greater corneal and conjunctival cell survival [14]. In an in vitro experiment for studying the effects of BAK on the human conjunctival cell line, BAK induced cell growth arrest and death even at a concentration of $0.0001 \%$. BAK-induced cell death was also dose-dependent - cells died by necrosis at higher concentrations of BAK and by apoptosis at lower concentrations of BAK [15]. Sherwood et al. reported an increased number of macrophages, lymphocytes, mast cells, and fibroblasts in the conjunctiva and Tenon's capsule and a significant decrease in the number of epithelial goblet cells in conjunctival biopsies of patients instilling anti-glaucoma medications for at least one year (mean 7.7 years) [16]. It has been shown that the success rate of trabeculectomies is higher in patients who had instilled topical anti-glaucoma medications only for two weeks compared to those who had instilled them for at least one year [17].
This perhaps is due to anti-glaucoma medications' effects on the conjunctival cells and fibroblasts, as demonstrated in the in vitro studies $[18,19]$. However, in these studies, it has not been clarified whether the effects was caused by the medication itself, the preservatives, or both. Mietz et al. reported a slight increase in antibodies against type IV collagen, $\alpha$-smooth muscle actin, and subepithelial collagen thickness in rabbit eyes treated with medications with preservatives while these effects were not seen in eyes treated with medications alone [20]. Uusitalo et al. studied HLA-DR positive conjunctival epithelial cells and MUC5AC expressing goblet cells in impression cytology specimens. Authors reported significant changes toward normalization during treatment with preservative-free tafluprost as opposed to with BAK-preserved latanoprost. These results suggest that preservative-free tafluprost has less harmful effects on the conjunctiva [10]. In order to limit adverse effects on the eye, it's essential to establish if the cytological changes are chiefly due to the preservatives' influence or the medications themselves.

\section{Cornea}

Burstein demonstrated cell lifting, peeling of epithelial cells, and exposure of underlying cell layers in rabbit and cat corneas when treated with $0.01 \%$ and $0.0075 \%$ BAK; the effect was much less significant with lower concentrations of BAK [21]. In an in vivo study, Kim et al. examined the effects of prostaglandin analogues with and without BAK on mouse ocular surface. In this study, severe punctuate epithelial keratitis was reported in eyes treated with BAK-containing drops. Also, surface desquamation, loss of cell borders, anisocytosis, and stromal shrinkage were noted in corneas treated with BAK-containing drops. Additionally, the corneas treated with BAK also showed decreased cell viability markers, increased apoptosis-inducing signals, and increased inflammatory cytokines [22]. Meda et al. reported that stopping chronic topical prostaglandin analogue treatment significantly increases corneal hysteresis, corneal resistance factor, and central corneal thickness, and reinitiation of therapy reverted these changes [23].

\section{PRESERVATIVES AND OCULAR TOLERANCE}

Uusitalo et al. presented results of two independent clinical phase IIIb studies [10, 24]. The studies' design was identical. Patients who developed 
signs and symptoms of OCD while on treatment with latanoprost containing $0.02 \%$ benzalkonium chloride were switched to receive preservative-free tafluprost and were evaluated for 12 weeks. During follow-up after switching to preservative-free tafluprost, a statistically significant shift toward less severe symptoms such as burning, stinging, foreign body sensation, itching, and dry eye sensation, was seen after six weeks. A continued improvement was observed starting from 6 to 12 weeks. At 12-weeks, among symptomatic at baseline patients, the proportion of patients treated with preservative-free tafluprost was only around one-third of patients using latanoprost. Likewise, there was a reported decrease in the frequency distribution of ocular signs after the switch. The severity of conjunctival hyperemia reportedly got reduced to half over the 12-week treatment period. The incidence of hyperemia also got reduced.

Regarding drop discomfort, there was a significant increase in the percentage of patients who had reported no drop discomfort after 12 weeks of treatment with preservative-free tafluprost. Furthermore, most of the patients preferred preservative-free tafluprost as opposed to preserved latanoprost. Up to $72 \%$ of the patients favored tafluprost, while only $6 \%$ opted for latanoprost in terms of medication preference [25].

Shedden et al. obtained opposite results. The authors performed a double-masked study in which 261 patients were having either primary open-angle glaucoma (POAG) or ocular hypertension (OHT). Patients were randomized to receive either a preservative-free preparation of dorzolamide/timolol combination or one containing $0.0075 \%$ BAK. The authors reported both the formulations to be well tolerated. There was no statistical difference between the two formulations in terms of adverse effects clinically. A similar proportion of patients in each group had punctate epithelial erosions. Three patients in the BAK group had to discontinue their medication due to adverse effects, while four patients in the preservative-free group discontinued their treatment due to it's side effects [26].

Sezgin Akçay et al. carried out a prospective study comparing the toxic effect of polyquaternium- (PQ) and benzalkonium chloride- (BAK) preserved travoprost on the ocular surface. On the basis of impression cytological examination, ocular surface disease index (OSDI) questionnaire, Schirmer test, and tear film break up time (TBUT) measurements, the authors made their observations. Based on their observations, the authors concluded that PQ-preserved travoprost was safer and better-tolerated than BAK-preserved travoprost; also, PQ-preserved travoprost reportedly provided better ocular surface comfort and hence led to better patient experience [27].

Goldberg et al. performed a double-masked randomized controlled trial comparing bimatoprost $0.03 \% /$ timolol $0.5 \%$ combination with and without BAK $(0.005 \%)$ in 561 patients with either POAG or OHT. Adverse effects were reported in an equal percentage of patients in the preservative-free and BAK groups ( $28.8 \%$ and $28.7 \%$, respectively). Conjunctival hyperemia was the most common adverse effect. No statistically significant difference was seen between the two groups in terms of conjunctival hyperemia, itching, dry eye, pain, eyelash growth, and lid erythema [28].

Crichton et al. conducted a randomized, multicenter study with the investigator's blinding to compare the ocular surface tolerability of $0.02 \%$ BAK-preserved bimatoprost, $0.02 \%$ BAK-preserved latanoprost, and SofZia-preserved travoprost in patients with POAG or OHT. In this study all newly diagnosed patients were put on latanoprost monotherapy for 30 days. At the end of that period, they were randomized into three groups with a 1:1:1 ratio: bimatoprost (preserved with BAK) group; latanoprost (preserved with BAK) group; travoprost (SofZia-preserved) group.

The authors reported no statistically significant differences in conjunctival hyperemia, corneal staining, or tear-breakup time among the three groups, not at baseline or at 12 weeks follow-up. Also, the three treatments were well tolerated by the patients, and adverse events were sparse and comparable across the groups [8].

In the previously cited study by Aihara et al., changing the treatment from BAK-preserved latanoprost to SofZia-preserved travoprost after three months of treatment with the former did not cause a significant change in the frequency of keratoconjunctival epitheliopathy in patients who continued with BAK-preserved latanoprost. However, a significant decrease was observed in patients who were switched to SofZia-preserved travoprost. Regarding the frequency of superficial punctuate keratitis (SPK), the authors found that the frequency of SPK improved significantly in the group that switched from BAK-preserved latanoprost to SofZia-preserved travoprost [7].

Ranno et al. compared the effects of tafluprost with other BAK-preserved prostaglandin analogs in 
a prospective study. The analysis of OCD showed no statistical difference between BAK-preserved latanoprost and unpreserved tafluprost and between BAK-preserved travoprost and unpreserved tafluprost. However, BAK-preserved bimatoprost induced a slightly higher conjunctival hyperemia and punctuated keratitis than unpreserved tafluprost [29].

Hamacher et al. performed a randomized crossover trial evaluating the pharmacodynamics and safety of preserved and preservative-free tafluprost eye drops. In this study, both the preserved and non-preserved formulations were well-tolerated by the patients, and ocular adverse effects were mild. No serious adverse effects were reported. For the preservative-free formulation, slightly higher ocular adverse events were reported as compared to the preserved formulation. The most frequently reported adverse event in both groups was conjunctival hyperemia. The incidence of conjunctival hyperemia was reported more frequently by patients using the preservative-free tafluprost as opposed to the preserved formulation [30].

In another similar study in healthy volunteers, comparable incidences of conjunctival hyperemia have been reported for both the preservative-free and the preserved formulations. However, the hyperemia was mostly of moderate severity with preserved tafluprost, while with preservative-free tafluprost, it was of mild severity [31].

In a multicenter cross-sectional epidemiologic survey in four European countries, Jaenen et al. compared the prevalence of side effects between eyedrops with or without preservatives regarding subjective symptoms and objective signs in POAG patients. Authors reported that all the studied symptoms and signs like pain or discomfort during instillation, stinging, foreign body sensation, and dry eye sensation were more significant in patients using eye drops with preservatives than patients using preservative-free drops. There was a significant decrease in the ocular signs and symptoms after switching from the preserved eye drops to preservative-free ones [32].

Rossi et al. reported that the presence of dry eye disease in topically treated glaucoma patients bears a negative influence on the patients' quality of life [33].

\section{PRESERVATIVES AND DRUG EFFICACY}

In the randomized crossover trial conducted by Hamacher et al., there was a similar reduction in intraocular pressure (IOP) (more than $5 \mathrm{~mm}$ $\mathrm{Hg}$ ) with both preservative-free tafluprost and BAK-preserved $(0.1 \mathrm{mg} / \mathrm{mL})$ tafluprost at the end of 1 week of therapy. The IOP lowering effect was maintained and was similar in both the groups at four weeks [30]. Kanamoto et al. performed a prospective randomized crossover trial evaluating BAK toxicity. Authors compared tafluprost with $0.001 \%$ BAK, and travoprost preserved with SofZia. There was no significant difference in IOP lowering in the two groups [34]. Rouland et al. compared the IOP reducing efficacy and safety of preservative-free latanoprost to BAK-preserved latanoprost in a prospective randomized trial. In the study, patients who previously instilled BAK-preserved latanoprost were randomized into two groups after a wash-out period. One group received preservative-free latanoprost, while the other group received BAK-preserved latanoprost. Over 84 days, the mean IOP reduction was similar in the two groups (similar efficacy), while local tolerance was better with the preservative-free formulation [35]. Goldberg et al. compared the efficacy of bimatoprost/timolol preservative-free with BAK-preserved bimatoprost/timolol. They reported the preservative-free formulation to be non-inferior to the preserved formulation in terms of IOP lowering from baseline at 12 weeks [28].

\section{PRESERVATIVES AND OCULAR FLORA}

Ohtani et al. have investigated the impact of long-term administration of BAK-preserved latanoprost $(0.005 \%)$ eye drops and SofZia-preserved travoprost $(0.004 \%)$ eye drops as monotherapy. $\mathrm{Pa}$ tients who were instilling the two drops for $>1$ year were enrolled in this study. Their conjunctival scrapings were collected as a specimen and were cultured for isolating bacterial isolates. The authors also tested for the isolates' drug susceptibility by measuring the minimum inhibitory concentrations (MIC50 and MIC90) of antibiotics (levofloxacin, gatifloxacin, moxifloxacin, cefmenoxime, ceftazidime, tobramycin, chloramphenicol, and erythromycin) as target antimicrobial agents against the obtained isolates. The authors reported that the frequency of isolation of MRSE (methicillin-resistant Staphylococcus aureus) was significantly higher in patients instilling BAK-preserved latanoprost. In contrast, the patients on SofZia-preserved travoprost and healthy controls did not. The authors also found that the MIC50 and MIC90 values for levofloxacin, gatifloxacin, moxifloxacin, cefmenox- 
ime, tobramycin, and erythromycin against the $S$. epidermidis isolates from the patients on BAK-preserved latanoprost were significantly higher than those against isolates from the patients on BAK-free travoprost. The authors also reported that the occurrence of multiple antibiotic-resistant S. epidermidis (resistant against more than three antibiotics among: one or more of levofloxacin, gatifloxacin, and moxifloxacin, one or more of ceftazidime and cefmenoxime, tobramycin, chloramphenicol, and erythromycin) was significantly higher in the patients using BAK-containing latanoprost compared to the patients on BAK-free travoprost and healthy volunteers. The authors concluded that the indigenous conjunctival flora might be influenced by an increase in MRSE by the long-term use of prostaglandin analogues [36].

Honda et al. studied the effects of chronic use ( $\geq 1$ year) of anti-glaucoma drops on conjunctival bacterial flora. An interesting outcome reported by the authors was that the culture positive rate was significantly lower in the patients instilling eye drops as compared to controls who were not on any eye drops [37]. Contrary to this, the culture positive rate was higher in patients with glaucoma than in healthy folks in another similar study by Sen et al. [38]. The reason for this disparity is likely owing to the difference in follow-up periods [37].

\section{PRESERVATIVES AND ANTERIOR CHAMBER Anterior chamber flare}

Kestelyn et al. reported a statistically significant drop in anterior chamber flare just one month after switching from BAK-containing latanoprost to preservative-free latanoprost. The flare value decreased further after two months and after three months [39]. In a previous study by the same authors (Kestelyn et al.), patients were randomly assigned to either BAK-preserved timolol or preservative-free timolol after recording baseline $\mathrm{AC}$ flare values. After a 1-month follow-up, AC flare values were measured again. There was an increase in AC flare in both groups, but the increase in the BAK-preserved timolol group was more significant than in the preservative-free group [40]. Abe et al. conducted a randomized study in which pseudophakic patients were randomized to either BAK-preserved artificial tears or preservative-free artificial tears four times a day for 30 days after baseline AC flare values and macular thicknesses were recorded. After 30 days of follow-up, the
BAK-preserved group showed a statistically significant increase in mean AC flare values compared to baseline. The preservative-free group did not show a significant increase from baseline values. However, the authors did not note any significant increase in macular thickness in either group. The authors concluded that short-term BAK exposure causes disruption of blood-aqueous barriers but not blood-retinal barriers in pseudophakic eyes [41].

\section{Trabecular meshwork}

In an in vitro study by Samples et al., BAK inhibited trabecular meshwork cells' growth, and these cells were also susceptible to BAK [42]. According to Hamard et al., unpreserved beta-blockers have no pro-apoptotic effect on human trabecular meshwork cells. However, BAK-containing beta-blockers increased one pro-apoptotic marker, while treatment with pure BAK caused $95 \%$ of the cells to undergo apoptosis. The authors inferred that while BAK-preserved beta-blockers and prostaglandin analogues marginally increased only one out of three pro-apoptotic markers. The pro-apoptotic effect observed with pure BAK was inhibited by other active compounds present in the preserved topical eye drop formulation [43]. BAK had been detected in trabecular meshwork and iris by time-of-flight secondary ion mass spectroscopy and chromatography coupled with mass spectrography [44].

\section{Lens}

In the Blue Mountains Eye Study, anti-glaucoma medications have increased the odds, albeit insignificant statistically, for nuclear cataracts [45]. It has been suggested that chronic BAK exposure induces cell stress to the lens epithelium cells and induce cataract [46].

\section{BAK AND POST-OPERATIVE INFLAMIMATION}

According to several studies, BAK itself is more responsible than the active drugs (i.e. latanoprost or timolol) in anti-glaucoma drops for inducing early post-operative inflammation caused by disrupting the blood-aqueous barrier [46-48]. Goto et al. reported that PGE2 expression is increased by latanoprost and timolol, especially in the presence of BAK. The authors suggested that BAK, by inducing prostaglandins, causes post-operative cystoids macular edema after cataract surgery or glaucoma surgery [46]. 


\section{BAK AND TRABECULECTOMY FAILURE}

The Preservative Exposure and Surgical Outcome Study (PESO study) retrospectively reviewed 128 glaucoma patients who undergone trabeculectomy and been treated with anti-glaucoma medication(s) preoperatively for variable periods. The authors found that the time to surgical failure was shorter in patients preoperatively receiving higher daily doses of BAK as a preservative of their anti-glaucoma eye drops than in patients receiving lower BAK doses. It was clearly evident that preoperative exposure to $\mathrm{BAK}$ is a risk factor for early trabeculectomy failure [49]. However, contrary to the PESO study results, in another study, 215 eyes that underwent trabeculectomy surgery were reviewed retrospectively. The authors did not find any significant negative effect of the preoperatively used anti-glaucoma drugs on the outcome of trabeculectomy [50]. Broadway et al. stopped sympathomimetic drops 30 days before filtration surgery in glaucoma patients and started them on fluorometholone $1 \%$ four times a day. The authors reported a decrease in fibroblasts and inflammatory cells in the conjunctiva [51]. Thus, it is suggestive that topical drugs induce inflammatory changes and have fibrosis-inducing effects that may influence the outcome of trabeculectomy. This inflammatory effect is most likely exerted by the preservative BAK present in topical anti-glaucoma medications [52].

\section{CONCLUSION}

Benzalkonium chloride (BAK) has many adverse effects on the ocular surface, including tear film stability, conjunctiva, and cornea. Also, long-term effects include a possible decrease in susceptibility of ocular bacterial flora to commonly used antibiotics and an increase in the incidence of Methicillin-resistant strains. Chronic exposure to BAK has been linked to an increased risk of trabeculectomy failure. Whether BAK-preserved drops are associated with more discomforting symptoms than preservative-free formulations is a matter of debate given the number of contradictory studies. Nevertheless, a good number of studies have pointed towards more discomfort and redness with BAK-preserved formulations. Keeping these facts in mind, preservative-free formulations or BAK-free formulations may be preferred over BAK-preserved ones while prescribing, especially anti-glaucoma medications, as these medications need to be instilled for long periods if not life-long. With more and more pharma- ceutical companies shifting to preparing BAK-free formulations, a paradigm shift is imminent. Ophthalmologists, on the other hand, must pave the way for the same by choosing to prescribe BAK-free formulations whenever possible.

\section{REFERENCES}

1. Becquet F, Goldschild M, Moldovan MS, et al. Histopathological effects of topical ophthalmic preservatives on rat corneoconjunctival surface. Curr Eye Res. 1998; 17(4): 419-425, doi: 10.1080/02713689808951223, indexed in Pubmed: 9561834.

2. Freeman P, Kahook M. Preservatives in topical ophthalmic medications: historical and clinical perspectives. Exp Rev Ophthalmol. 2014; 4(1): 59-64, doi: 10.1586/17469899.4.1.59.

3. Noecker RJ, Herrygers LA, Anwaruddin R. Corneal and conjunctival changes caused by commonly used glaucoma medications. Cornea. 2004; 23(5): 490-496, doi: 10.1097/01.ico.0000116526.57227.82, indexed in Pubmed: 15220734.

4. Kahook M. Travoprost Z ophthalmic solution with sofZia: clinical safety and efficacy. Exp Rev Ophthal. 2014; 2(3): 363-368, doi: 10.1586/17469899.2.3.363.

5. Tomić M, Kaštelan S, Soldo KM, et al. Influence of BAK-preserved prostaglandin analog treatment on the ocular surface health in patients with newly diagnosed primary open-angle glaucoma. Biomed Res Int. 2013; 2013: 603782, doi: 10.1155/2013/603782, indexed in Pubmed: 23971041.

6. Baudouin C, de Lunardo C. Short-term comparative study of topical $2 \%$ carteolol with and without benzalkonium chloride in healthy volunteers. Br J Ophthalmol. 1998; 82(1): 39-42, doi: 10.1136/bjo.82.1.39, indexed in Pubmed: 9536878.

7. Aihara M, Oshima H, Araie M, et al. EXTraKT study group. Effects of SofZia-preserved travoprost and benzalkonium chloride-preserved latanoprost on the ocular surface -- a multicentre randomized singlemasked study. Acta Ophthalmol. 2013; 91(1): e7-ee14, doi: 10.1111/j. 1755-3768.2012.02565.x, indexed in Pubmed: 23241328.

8. Crichton ACS, Vold S, Williams JM, et al. Ocular surface tolerability of prostaglandin analogs and prostamides in patients with glaucoma or ocular hypertension. Adv Ther. 2013; 30(3): 260-270, doi: 10.1007/ s12325-013-0014-7, indexed in Pubmed: 23475405.

9. Rossi GC, Tinelli C, Pasinetti GM, et al. Dry eye syndrome-related quality of life in glaucoma patients. Eur J Ophthalmol. 2009; 19(4): 572-579, doi: 10.1177/112067210901900409, indexed in Pubmed: 19551671.

10. Uusitalo $H$, Chen E, Pfeiffer N, et al. Switching from a preserved to a preservative-free prostaglandin preparation in topical glaucoma medication. Acta Ophthalmol. 2010; 88(3): 329-336, doi: 10.1111/j. 1755-3768.2010.01907.x, indexed in Pubmed: 20546237.

11. Ashraf H, Ahmad S, Sarkar R, et al. Topical Prostaglandin Analogues with and without Preservatives on Tear Film Stability in the Long-Term Treatment of Glaucoma. J Evid Based Med Healthc. 2020; 7(16): 823-826, doi: 10.18410/jebmh/2020/178.

12. Kim EJ, Kim YH, Kang SH, et al. In vitro effects of preservative-free and preserved prostaglandin analogs on primary cultured human conjunctival fibroblast cells. Korean J Ophthalmol. 2013; 27(6): 446-453, doi: 10.3341/kjo.2013.27.6.446, indexed in Pubmed: 24311931.

13. Baudouin C, Riancho L, Warnet JM, et al. In vitro studies of antiglaucomatous prostaglandin analogues: travoprost with and without benzalkonium chloride and preserved latanoprost. Invest Ophthalmol Vis Sci. 2007; 48(9): 4123-4128, doi: 10.1167/iovs.07-0266, indexed in Pubmed: 17724196.

14. Ammar DA, Noecker RJ, Kahook MY. Effects of benzalkonium chloride-preserved, polyquad-preserved, and sofZia-preserved topical glaucoma medications on human ocular epithelial cells. Adv Ther. 2010; 27(11): 837-845, doi: 10.1007/s12325-010-0070-1, indexed in Pubmed: 20931366.

15. De Saint Jean M, Brignole F, Bringuier AF, et al. Effects of benzalkonium chloride on growth and survival of Chang conjunctival cells. Invest Ophthalmol Vis Sci. 1999; 40(3): 619-630, indexed in Pubmed: 10067965. 
16. Sherwood MB, Grierson I, Millar L, et al. Long-term morphologic effects of antiglaucoma drugs on the conjunctiva and Tenon's capsule in glaucomatous patients. Ophthalmology. 1989; 96(3): 327-335, doi: 10.1016/s0161-6420(89)32888-0, indexed in Pubmed: 2710524.

17. Lavin MJ, Wormald RP, Migdal CS, et al. The influence of prior therapy on the success of trabeculectomy. Arch Ophthalmol. 1990; 108(11): 1543-1548, doi: 10.1001/archopht.1990.01070130045027, indexed in Pubmed: 2244836.

18. Williams DE, Nguyen KD, Shapourifar-Tehrani $S$, et al. Effects of timolol, betaxolol, and levobunolol on human tenon's fibroblasts in tissue culture. Invest Ophthalmol Vis Sci. 1992; 33(7): 2233-2241, indexed in Pubmed: 1607234.

19. Takahashi N. [Cytotoxic effects of antiglaucoma agents on cultured human conjunctival cells (author's transl)]. Nippon Ganka Gakkai Zasshi. 1981; 85(8): 1046-1052, indexed in Pubmed: 7315632.

20. Mietz H, Niesen U, Krieglstein GK. The effect of preservatives and antiglaucomatous medication on the histopathology of the conjunctiva. Graefes Arch Clin Exp Ophthalmol. 1994; 232(9): 561-565, doi: 10.1007/BF00182000, indexed in Pubmed: 7959096.

21. Burstein NL. Preservative cytotoxic threshold for benzalkonium chloride and chlorhexidine digluconate in cat and rabbit corneas. Invest Ophthalmol Vis Sci. 1980; 19(3): 308-313, indexed in Pubmed: 7358482.

22. Kim JH, Kim EJ, Kim YH, et al. In Vivo Effects of Preservative-free and Preserved Prostaglandin Analogs: Mouse Ocular Surface Study. Korean J Ophthalmol. 2015; 29(4): 270-279, doi: 10.3341/kjo.2015.29.4.270, indexed in Pubmed: 26240512.

23. Meda R, Wang Q, Paoloni D, et al. The impact of chronic use of prostaglandin analogues on the biomechanical properties of the cornea in patients with primary open-angle glaucoma. Br J Ophthalmol. 2017; 101(2): 120-125, doi: 10.1136/bjophthalmol-2016-308432, indexed in Pubmed: 27162226.

24. Egorov EA, Astahov Y, Erichev VP, et al. Evaluation of efficacy and safety of preservative-free tafluprost 0, 0015\% eye drops in POAG and ophthalmohypertension. RMJ Clin Ophthalmol. 2015; 15(1): 1-6.

25. Uusitalo H, Egorov E, Kaarniranta K, et al. Benefits of switching from latanoprost to preservative-free tafluprost eye drops: a meta-analysis of two Phase Illb clinical trials. Clin Ophthalmol. 2016; 10: 445-454, doi: 10.2147/OPTH.S91402, indexed in Pubmed: 27041987.

26. Shedden A, Adamsons IA, Getson AJ, et al. Comparison of the efficacy and tolerability of preservative-free and preservative-containing formulations of the dorzolamide/timolol fixed combination (COSOPT ${ }^{\mathrm{TM}}$ ) in patients with elevated intraocular pressure in a randomized clinical trial. Graefes Arch Clin Exp Ophthalmol. 2010; 248(12): 1757-1764, doi: 10.1007/s00417-010-1397-7, indexed in Pubmed:20437244.

27. Sezgin Akçay Bi, Güney E, Bozkurt TK, et al. Effects of polyquaternium- and benzalkonium-chloride-preserved travoprost on ocular surfaces: an impression cytology study. J Ocul Pharmacol Ther. 2014; 30(7): 548-553, doi: 10.1089/jop.2013.0248, indexed in Pubmed: 24901262.

28. Goldberg I, Gil Pina R, Lanzagorta-Aresti A, et al. Bimatoprost 0.03\%/ timolol $0.5 \%$ preservative-free ophthalmic solution versus bimatoprost $0.03 \% /$ timolol $0.5 \%$ ophthalmic solution (Ganfort) for glaucoma or ocular hypertension: a 12-week randomised controlled trial. Br J Ophthalmol. 2014; 98(7): 926-931, doi: 10.1136/bjophthalmol-2013-304064, indexed in Pubmed: 24667994.

29. Ranno S, Sacchi M, Brancato C, et al. A prospective study evaluating IOP changes after switching from a therapy with prostaglandin eye drops containing preservatives to nonpreserved tafluprost in glaucoma patients. ScientificWorldJournal. 2012; 2012: 804730, doi: 10.1100/2012/804730, indexed in Pubmed: 22606063.

30. Hamacher T, Airaksinen J, Saarela V, et al. Efficacy and safety levels of preserved and preservative-free tafluprost are equivalent in patients with glaucoma or ocular hypertension: results from a pharmacodynamics analysis. Acta Ophthalmol Suppl (0xf ). 2008; 242: 14-19, doi: 10.1111/j.1755-3768.2008.01381.x, indexed in Pubmed: 18752510.

31. Uusitalo H, Kaarniranta K, Ropo A. Pharmacokinetics, efficacy and safety profiles of preserved and preservative-free tafluprost in healthy volunteers. Acta Ophthalmol Suppl (0xf ). 2008; 242: 7-13, doi: 10.1111/j. 1755-3768.2008.01380.x, indexed in Pubmed: 18752509.
32. Jaenen N, Baudouin C, Pouliquen P, et al. Ocular symptoms and signs with preserved and preservative-free glaucoma medications. Eur $\mathrm{J}$ Ophthalmol. 2007; 17(3): 341-349, doi: 10.1177/11206721070170 0311, indexed in Pubmed: 17534814.

33. Rossi GC, Tinelli C, Pasinetti GM, et al. Dry eye syndrome-related quality of life in glaucoma patients. Eur J Ophthalmol. 2009; 19(4): 572-579, doi: 10.1177/112067210901900409, indexed in Pubmed: 19551671.

34. Kanamoto T, Kiuchi Y, Tanito M, et al. Ocular Surface Disease and Glaucoma Study Group. Comparison of the toxicity profile of benzalkonium chloride-preserved tafluprost and SofZia-preserved travoprost applied to the ocular surface. J Ocul Pharmacol Ther. 2015; 31(3): 156-164, doi: 10.1089/jop.2014.0104, indexed in Pubmed: 25710276.

35. Rouland JF, Traverso CE, Stalmans I, et al. T2345 Study Group. Efficacy and safety of preservative-free latanoprost eyedrops, compared with BAK-preserved latanoprost in patients with ocular hypertension or glaucoma. Br J Ophthalmol. 2013; 97(2): 196-200, doi: 10.1136/ bjophthalmol-2012-302121, indexed in Pubmed: 23203707.

36. Ohtani S, Shimizu K, Nejima R, et al. Conjunctival Bacteria Flora of Glaucoma Patients During Long-Term Administration of Prostaglandin Analog Drops. Invest Ophthalmol Vis Sci. 2017; 58(10): 3991-3996, doi: 10.1167/iovs.16-20853, indexed in Pubmed: 28796877.

37. Honda $R$, Toshida $H$, Suto $C$, et al. Effect of long-term treatment with eyedrops for glaucoma on conjunctival bacterial flora. Infect Drug Resist. 2011; 4: 191-196, doi: 10.2147/IDR.S24250, indexed in Pubmed: 22114511.

38. Sen EM, Yilmaz MB, DansukZ, et al. Effect of chronic topical glaucoma medications on aerobic conjunctival bacterial flora. Cornea. 2009; 28(3): 266-270, doi: 10.1097/ICO.0b013e3181861c11, indexed in Pubmed: 19387226.

39. Kestelyn PhA, Kestelyn PhG, De Bacquer D, et al. Switch from BAK-preserved to preservative-free latanoprost decreases anterior chamber flare in POAG patients. Int Ophthalmol. 2019; 39(1): 105-109, doi: 10.1007/s10792-017-0792-z, indexed in Pubmed: 29274019.

40. Stevens AM, Kestelyn PA, De Bacquer D, et al. Benzalkonium chloride induces anterior chamber inflammation in previously untreated patients with ocular hypertension as measured by flare meter: a randomized clinical trial. Acta Ophthalmol. 2012; 90(3): e221-e224, doi: 10.1111/j. 1755-3768.2011.02338.x, indexed in Pubmed: 22489894.

41. Abe RY, Zacchia RS, Santana PR, et al. Effects of benzalkonium chloride on the blood-aqueous and blood-retinal barriers of pseudophakic eyes. J Ocul Pharmacol Ther. 2014; 30(5): 413-418, doi: 10.1089/ jop.2013.0227, indexed in Pubmed: 24660827.

42. Samples JR, Binder PS, Nayak S. The effect of epinephrine and benzalkonium chloride on cultured corneal endothelial and trabecular meshwork cells. Exp Eye Res. 1989; 49(1): 1-12, doi: 10.1016/00144835(89)90071-7, indexed in Pubmed: 2759185.

43. Hamard P, Blondin C, Debbasch C, et al. In vitro effects of preserved and unpreserved antiglaucoma drugs on apoptotic marker expression by human trabecular cells. Graefes Arch Clin Exp Ophthalmol. 2003; 241(12): 1037-1043, doi: 10.1007/s00417-003-0777-7, indexed in Pubmed: 14605906.

44. Desbenoit N, Schmitz-Afonso I, Baudouin C, et al. Localisation and quantification of benzalkonium chloride in eye tissue by TOF-SIMS imaging and liquid chromatography mass spectrometry. Anal Bioanal Chem. 2013; 405(12): 4039-4049, doi: 10.1007/s00216-013-6811-7, indexed in Pubmed: 23430186.

45. Chandrasekaran S, Cumming RG, Rochtchina E, et al. Associations between elevated intraocular pressure and glaucoma, use of glaucoma medications, and 5-year incident cataract: the Blue Mountains Eye Study. Ophthalmology. 2006; 113(3): 417-424, doi: 10.1016/j. ophtha.2005.10.050, indexed in Pubmed: 16458969.

46. Goto Y, Ibaraki N, Miyake K. Human lens epithelial cell damage and stimulation of their secretion of chemical mediators by benzalkonium chloride rather than latanoprost and timolol. Arch Ophthalmol. 2003; 121(6): 835-839, doi: 10.1001/archopht.121.6.835, indexed in Pubmed: 12796255.

47. Miyake K, Ota I, Ibaraki N, et al. Enhanced disruption of the bloodaqueous barrier and the incidence of angiographic cystoid macular edema by topical timolol and its preservative in early postoperative 
pseudophakia. Arch Ophthalmol. 2001; 119(3): 387-394, doi: 10.1001/ archopht.119.3.387, indexed in Pubmed: 11231772.

48. Miyake K, Ota I, Maekubo K, et al. Latanoprost accelerates disruption of the blood-aqueous barrier and the incidence of angiographic cystoid macular edema in early postoperative pseudophakias. Arch Ophthalmol. 1999; 117(1): 34-40, doi: 10.1001/archopht.117.1.34, indexed in Pubmed: 9930158.

49. Boimer C, Birt CM. Preservative exposure and surgical outcomes in glaucoma patients: The PESO study. J Glaucoma. 2013; 22(9): 730-735, doi: 10.1097/IJG.0b013e31825af67d, indexed in Pubmed: 23524856 .
50. Öztürker ZK, Öztürker C, Bayraktar S, et al. Does the use of preoperative antiglaucoma medications influence trabeculectomy success? J Ocul Pharmacol Ther. 2014; 30(7): 554-558, doi: 10.1089/jop.2014.0008, indexed in Pubmed: 24918962.

51. Broadway DC, Grierson I, Stürmer J, et al. Reversal of topical antiglaucoma medication effects on the conjunctiva. Arch Ophthalmol. 1996; 114(3): 262-267, doi: 10.1001/archopht.1996.01100130258004, indexed in Pubmed: 8600884.

52. Baudouin C. Mechanisms of failure in glaucoma filtering surgery: a consequence of antiglaucomatous drugs? Int J Clin Pharmacol Res. 1996; 16(1): 29-41, indexed in Pubmed: 9001927. 